\title{
Social Aspects of Malaria among Students in Two Tertiary Institutions in Lagos, Nigeria
}

\author{
Okwa Omolade 0*, Bello Babatunde A and Olundegun Simbiat A
}

Department of Zoology Faculty of Science Lagos State University, Lagos

\begin{abstract}
Studies were carried out on the social aspects of malaria among 600 students. Three hundred students (150 male, 150 females) were randomly selected from two tertiary institutions in Lagos, Nigeria. These schools are Lagos State University (LASU) and AOCOED (Adeniran Ogunsanya College of Education). A structured questionnaire elicited relevant information on knowledge, perception and social aspects of malaria. Students aged 21-23, from faculty of arts and in their second year participated mostly in the study with no significant difference between the two schools. In LASU, 223(74.3\%) and 211(70.3\%) in AOCOED knew the cause of malaria $(P>0.05)$. In LASU, $282(94 \%)$ and $192(64 \%)$ in AOCOED believed that malaria could be prevented $(P<0.05)$. In LASU, 283(96\%) and 283(94.3\%) in AOCOED believed malaria could be treated $(P>0.05) .109$ (36.3\%) respondents in LASU and 112(37.3\%) in AOCOED thought that malaria was contagious $(P>0.05)$. Fever was the most recognised symptom of malaria in both schools and self-medication was more popular in AOCOED. In LASU, 284(94.6\%) and AOCOED, 273(91\%) had malaria in the past one year $(P>0.05) .146(48.7 \%)$ of the students who participated in LASU and 206(68.6\%) in AOCOED had been admitted for malaria within the past one year $(P<0.05)$. Class absenteeism and low academic performance were significantly higher in AOCOED than LASU. However, our results suggested that the LASU students were more informed about malaria than the AOCOED students because their knowledge and perception was better. The students, despite their academic backgrounds need intensified health education on malaria incorporated into their schools' curriculum.
\end{abstract}

\section{Keywords: Academic performance, Knowledge and perception, Malaria, Socioeconomic status, Students}

Received 7 May 2011/ Accepted 02 August 2011

\section{INTRODUCTION}

Malaria is a serious impediment to social and economic development in Nigeria (Okwa et al., 2009). Malaria accounts for much of the disease burden in Nigeria, claiming thousands of life and causing massive economic losses (Onwujekwe et al., 2000). The socio-economic aspects of population are known to contribute significantly to the epidemiology and control of parasitic diseases (Ukoli, 1992). Nelson (1978) stated that the socioeconomic consequences of diseases are better appreciated when expressed as loss of manpower. Poverty has been asserted to promote malaria and malaria yields poverty (Sachs and Malaney, 2002). Socio-economic cost can be measured in terms of absenteeism, drugs purchase, doctor's fee, transport, and opportunity cost of time spent waiting for treatment. In Africa alone, the estimated annual direct and indirect costs of malaria were US\$800 million in 1987 and exceeded US\$1800 million by 1995 . In 1990, malaria was responsible for the loss of 31.7 million Disability Adjusted Life Years (DALYS) (WHO, 1999). Thus, without a rational concept of the nature of a disease, it is impossible to visualise a management procedure.

Knowledge, attitude and practices (KAP) are essential for control programmes. Elzubier et al. (1997) reported that there are wrong misconceptions of malaria even among students. Likewise, Okwa and Ibidapo (2010) reported that some students have erroneous perceptions of Malaria. Ndawala et al. (2000) revealed that rurality and lack of education accounted for more exposure and incidence of malaria. Fawole and Onadeko (2001) similarly found a relationship between level 
of education, marital status and knowledge of malaria. Morenikeji (2009) reported that few students had misconceptions about the aetiology of malaria in a secondary school in South-west, Nigeria. In another study elsewhere, the authors documented that all the students examined had thorough knowledge of malaria prophylaxis (Peetermanns and Winjingaerden, 2000). Muala and Chimalizeni (2004) reported that the knowledge and perception of malaria among students in Malawi was encouraging. However, Matta et al. (2004) reported inadequate knowledge and perception among symptomatic outpatients.

In Nigeria, malaria ranks among the five commonest cause of childhood deaths and also represent 25 to $30 \%$ of deaths of children under five (WHO, 1999). It is the commonest cause of outpatient visit in Nigeria and also the commonest cause of school and work absenteeism (Salako, 2001). Najera and Hempel (2006) reported that school absenteeism due to malaria was as high as $70 \%$. Leigton and Foster (1993) reported that in Kenya, 11\% primary school students and 4.3\% secondary school students missed school days per year due to malaria. They also reported that Nigerian school children missed an estimated 3-12 school days per year (2.6\%). Fernando et al. (2003) observed that there was significant adverse impact of repeated malaria attacks on school performance of children. Lallo (2004) stated that malaria is an important cause of adolescents' hospital admission in many sub-Saharan African countries.

In 2010, Okwa and Ibidapo examined the malaria situation in Lagos State University, Nigeria. This earlier study incorporated clinical, parasitological and knowledge and perception aspects (Okwa and Ibidapo, 2010). This present study follow-ups the study to examine and compare the knowledge, perception, socio-economic and academic effects of malaria on students in two tertiary institutions, Lagos State University and Adeniran Ogunsanya College of Education. This study aims to expose the predisposing social factors to malaria infection among students in the two tertiary institutions. The study also aims to quantify the socio-economic effects of malaria, a factor which could be used to enforce compliance to prevention of malaria.

\section{MATERIALS AND METHODS}

\section{Study Areas}

Two tertiary institutions were used in the study. They are the Lagos State University (LASU) at Ojo and Adeniran Ogunsanya College of Education (AOCOED) at Ijanikin, Nigeria. Both are located on Lagos-Badagry express road but about $30 \mathrm{kms}$ apart. The two schools are owned by the Lagos State government of Nigeria. Only LASU had a campus female hostel at the time of study. The male student in LASU and all students in AOCOED lived in private external hostels (PEH).

\section{Preparation of Questionnaire}

Structured questionnaires were used to elicit information from students. The questionnaire contained the aims and objectives of the research as stated above. Questions on the social aspects of malaria such as knowledge and perception, socioeconomic and academic effects were prepared. The questionnaire was then pretested by carrying out a pilot study using ten male and ten female students, randomly selected from each tertiary school. The pilot study enabled questions to be corrected, adjusted and discarded irrelevancies and ambiguities.

\section{Questionnaire Administration and Inclusion Criteria}

A total of 600 students were requited into the study; Three hundred (150 males and 150 females) from each school. These students were those that volunteered to fill the questionnaires. They were randomly selected from the hostels within and without: The questionnaires were administered simultaneously in both schools for a period of seven days. It took a maximum of fifteen minutes to fill each questionnaire and they were collected back immediately.

\section{Statistical Analysis}

Chi square $X^{2}$ was used to determine the differences in results between the two tertiary institutions and differences in values between male and female students. $P<0.05$ was regarded as an acceptable level of significance while $P>0.05$ was not significant at $5 \%$.

\section{RESULTS}

\section{Socio-academic Profile}

In both schools investigated, the students that participated were mostly from faculty of arts and most of the students were in their second year. However, the female students in AOCOED were mostly in their third year. No significant difference existed in the socio-academic profile of respondents in the two institutions $\left(X^{2}=0.67, P>0.05\right)$ (Table 1). 
Table 1: Socio-academic Profile of 300 Respondents each in LASU and AOCOED

\begin{tabular}{|c|c|c|c|c|c|c|}
\hline \multirow[b]{2}{*}{ Profiles } & \multicolumn{3}{|c|}{ LASU No (\%) } & \multicolumn{3}{|c|}{ AOCOED No (\%) } \\
\hline & Male & Female & Total & Male & Female & Total \\
\hline Age & & & & & & \\
\hline Below 17 & $0(0)$ & $1(0.67)$ & $1(0.33)$ & $42(28)$ & $3(2)$ & $45(15)$ \\
\hline $17-20$ & $35(23.3)$ & $21(14)$ & $56(18.17)$ & $45(30)$ & $27(18)$ & $72(24)$ \\
\hline $21-23$ & $84(56)$ & $72(48)$ & $156(52)$ & $58(3.33)$ & $49(32.7)$ & $107(35.7)$ \\
\hline $24-27$ & $26(17.3)$ & $48(32)$ & $74(24.7)$ & $59(3.33)$ & $55(36.7)$ & $60(30)$ \\
\hline Above 27 & $05(3.33)$ & $8(5.33)$ & $13(4.3)$ & $0(0)$ & $16(10.7)$ & $16(5.3)$ \\
\hline Faculties & & & & & & \\
\hline Education & $8(5.33)$ & $20(13.3)$ & $28(9.3)$ & $29(19.3)$ & $26(17.3)$ & $55(18.3)$ \\
\hline Science & $11(7.33)$ & $32(21.3)$ & $43(14)$ & $20(13.3)$ & $26(17.3)$ & $46(15.3)$ \\
\hline Languages & $0(0)$ & $0(0)$ & $0(0)$ & $06(4)$ & $18(12)$ & $24(8)$ \\
\hline Arts/S.sci & $60(40)$ & $46(20.7)$ & $106(35.3)$ & $74(49.3)$ & $68(45.3)$ & $142(47.3)$ \\
\hline Voc/Tech & $0(0)$ & $0(0)$ & $0(0)$ & $21(14)$ & $12(8)$ & $33(11)$ \\
\hline FMS & $32(21.3)$ & $28(18.7)$ & $60(20)$ & $0(0)$ & $0(0)$ & $\mathbf{0}(0)$ \\
\hline Law & $34(22.6)$ & $24(160$ & $58(19.3)$ & $0(0)$ & $0(0)$ & $0(0)$ \\
\hline Transport & $5(3.33)$ & $0(0)$ & $5(1.67)$ & $0(0)$ & $0(0)$ & $0(0)$ \\
\hline $\begin{array}{l}\text { Level of } \\
\text { Study } \\
\text { (year) }\end{array}$ & & & & & & \\
\hline 1ST & $26(17.3)$ & $22(14.6)$ & $48(16)$ & $47(32.3)$ & $31(20.6)$ & $78(26)$ \\
\hline 2ND & $82(54.7)$ & $90(60)$ & $172(57.3)$ & $70(46.7)$ & $85(56.6)$ & $155(51.7)$ \\
\hline 3RD & $33(22)$ & $15(10)$ & $49(16.3)$ & $26(17.3)$ & $14(9.33)$ & $40(13.3$ \\
\hline 4TH & $06(4)$ & $23(15.3)$ & $29(9.7)$ & $07(4.7)$ & $10(6.66)$ & $17(5.7)$ \\
\hline $5^{\mathrm{TH}}$ & $03(2)$ & $0(0)$ & $03(1)$ & $0(0)$ & $10(6.66)$ & $10(3.33)$ \\
\hline
\end{tabular}

Knowledge and Perception of the Cause and Symptoms of Malaria

In LASU, 134(89.3\%) of female and 89(59.3\%) of male respondents knew that mosquitoes transmit malaria through their bites $\left(X^{2}=1.23, P>0.05\right)$. In AOCOED, 125(83.3\%) of females and 86(57.3\%) male respondents also knew the cause of malaria $\left(X^{2}=1.25, P>0.05\right)$. In LASU, 91(60.7\%) of female and $100(66.6 \%)$ of male respondents believed that malaria is not transmissible or contagious $\left(X^{2}=1.5\right.$, $P>0.05)$. In AOCOED, 56 (37.3\%) of female and $132(88 \%)$ of male respondents, also believed that malaria is not transmissible $\left(X^{2}=3.88, P<0.05\right)$ (Table 2). Fever was the most recognised symptoms in both schools, while body pain and weakness were exclusively recognised by female respondents only (Figure 1).

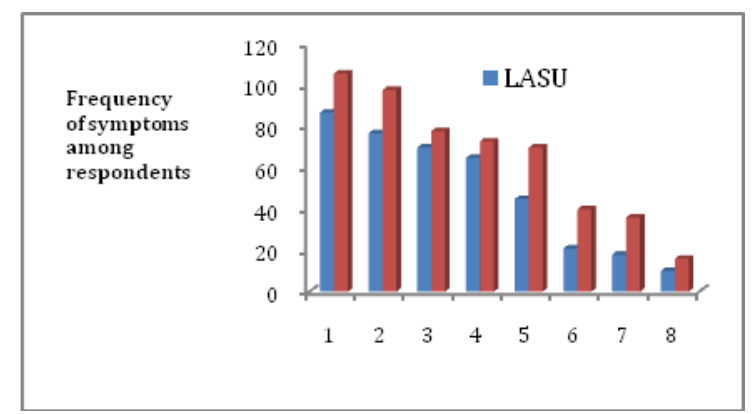

1: fever, 2: weakness, 3 : headache, 4 : coloured urine, 5 : body pain, 6 : joint pain, 7 : painful-eyes, 8 : others

Figure 1: Symptoms of Malaria among Respondents
Knowledge and Perception of the Prevention and Treatment of Malaria

In LASU, 135 (90\%) of female and 147 (98\%) of male respondents upheld that malaria can be prevented $\left(X^{2}=1.78, P>0.05\right)$. In AOCOED, 97 (64.6\%) female and 145 (96.6\%) male respondent also had this view $\left(X^{2}=3.86, P<0.05\right)$. In LASU, 142 (94.6\%) females and $146 \quad(97.3 \%)$ male respondents believed that malaria can be treated $\left(X^{2}=0.07, P>0.05\right)$. In AOCOED, 133(88.1\%) females and all male respondents believed this also $\left(X^{2}=1.56, P>0.05\right)$ (Table 3$)$.

\section{Treatment Seeking}

A larger part of the students preferred self medication. While 125 (44.1\%) female students from AOCOED preferred self medication, $110(38.1 \%)$ males in LASU had a propensity towards self-medication $\left(X^{2}=0.66, P>0.05\right)$. Seeking treatment from doctors was the second option after self medication in both schools. This option was common among female in LASU $\{108(76 \%)\}$ and AOCOED $\{64(48.1 \%)\}\left(X^{2}=1.77, P>0.05\right)$. Prayer was mentioned by $8(6 \%)$ of students in AOCOED only (Table 3).

\section{Malaria Status}

$123(82 \%)$ of female and all male respondents from AOCOED had malaria in the past one year. 134(89.3\%) from LASU and all male student also indicated they had malaria in the past one year. 
Hence there was more malaria infection in LASU $\{284(94.6 \%)\}$ than AOCOED $\{273(91 \%)\}$ but no significant difference existed $\left(X^{2}=1.02, \quad P>0.05\right)$. Incidence of hospital admission was higher in AOCOED, 206 (68.6\%) than LASU, 146(48.7\%) $\left(X^{2}=1.34, P>0.05\right)$ (Figures $2 \mathrm{a}$ and $2 \mathrm{~b}$ ).
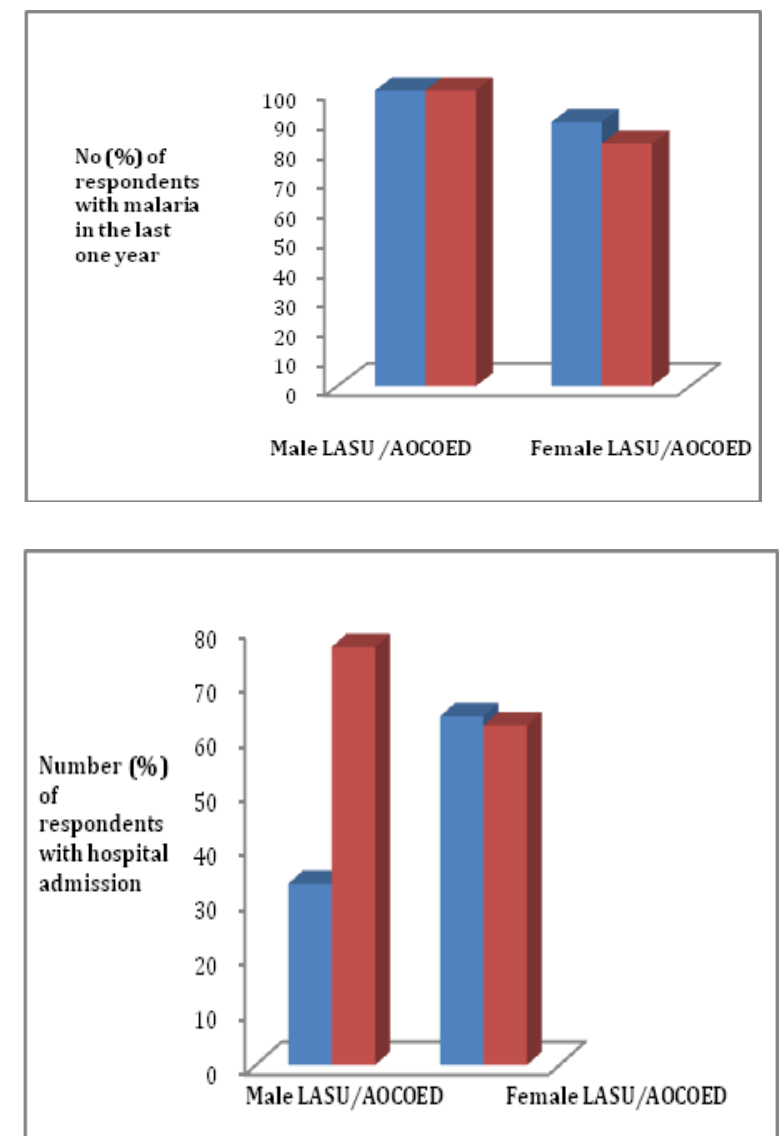

Figure 2a: Percentage of Respondents that had Malaria

Figure 2b: Hospital Admission due to Malaria among Respondents

\section{Socioeconomic Effects}

Class absenteeism was higher in AOCOED, 214(71.3\%) than LASU, 164 (54.4\%). In LASU, 86(57.3\%) females and 78(52\%) males had missed classes $\left(X^{2}=1.03, P>0.05\right)$. In AOCOED, 140(93.3\%) males and 74(49.3\%) females had missed classes ( $P>0.05$ ) (Table 4). The highest amount spent on drugs by respondents was between N100-N500 in both schools, $134(44.6 \%)$ in LASU and $133(44.3 \%)$ in AOCOED $\left(X^{2}=1.00, P>0.05\right) .66(22 \%)$ students in LASU and $72(24 \%)$ in AOCOED spend over N1000 on drugs. Irrespective of sex, fathers of students in both schools were predominantly public officers and mothers were mostly traders. Unemployed parents of students were also indicated (Table 4). Other effects of malaria on academic performances are shown in Figure 3.

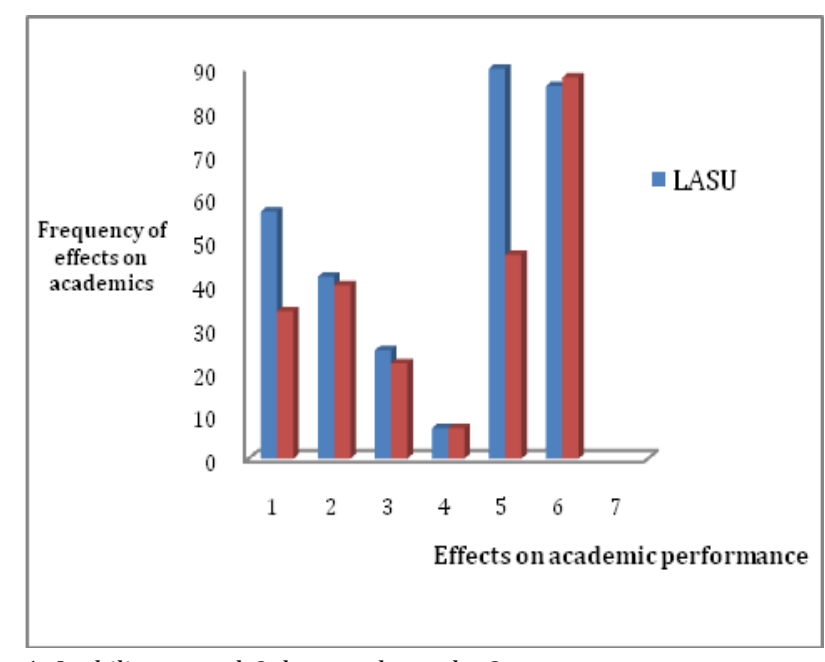

1: Inability to read, 2: low grade marks, 3: carry over course,

4: extra semester 5: rewriting of test, 6: missed exam.

Figure 3: Effect of Malaria on Academic Performance

Table 2: Knowledge and Perception of the Cause of Malaria among the 600 Respondents

\begin{tabular}{|l|l|l|l|l|l|l|}
\hline \multirow{2}{*}{ Cause of Malaria } & \multicolumn{3}{|l|}{ LASU No (\%) } & \multicolumn{2}{l|}{ AOCOED No (\%) } \\
\cline { 2 - 7 } & Male & Female & Total & Male & Female & Total \\
\hline Mosquito bite & $89(59.3)$ & $134(89.3)$ & $223(74.3)$ & $86(57.3)$ & $125(83.3)$ & $211(70.3)$ \\
Stress & $55(36.6)$ & $03(2)$ & $58(19.3)$ & $55(36.7)$ & $15(10$ & $70(23.3)$ \\
Alcohol & $05(3.33)$ & $05(3.33)$ & $10(3.33)$ & $01(0.67)$ & $04(2.67)$ & $05(1.67)$ \\
Contact & $0(0)$ & $02(1.33)$ & $02(0.67)$ & $02(1.33)$ & $03(2)$ & $05(1.67)$ \\
Heat/sun & $1(0.67)$ & $05(3.33)$ & $06(2)$ & $06(4)$ & $4(2.67)$ & $10(3.33)$ \\
Others & $0(0)$ & $01(0.67)$ & $01(0.33)$ & $0(0)$ & $2(1.33)$ & $02(0.67)$ \\
\hline Is malaria & & & & & & \\
contagious? & & & & & & \\
Yes & & & & & & \\
No & $50(33.3)$ & $59(39.3)$ & $109(36.3)$ & $18(12)$ & $94(62.7)$ & $112(37.3)$ \\
& $100(66.6)$ & $91(60.7)$ & $191(63.6)$ & $132(88)$ & $56(37.3)$ & $188(62.7)$ \\
& & & & & & \\
\hline
\end{tabular}


Table 3: Knowledge and Perception of the Prevention and Treatment of Malaria among the 600 Respondents

\begin{tabular}{|c|c|c|c|c|c|c|}
\hline & \multicolumn{3}{|c|}{ LASU No (\%) } & \multicolumn{3}{|c|}{ AOCOED No (\%) } \\
\hline & Male & Female & Total & Male & Female & Total \\
\hline $\begin{array}{l}\text { Can malaria be prevented? } \\
\text { Yes } \\
\text { No }\end{array}$ & $\begin{array}{l}147(98) \\
03(2)\end{array}$ & $\begin{array}{l}135(90) \\
15(10)\end{array}$ & $\begin{array}{l}282(94) \\
18(6)\end{array}$ & $\begin{array}{l}145(96.6) \\
05(3.33)\end{array}$ & $\begin{array}{l}97(64.6) \\
53(35.3)\end{array}$ & $\begin{array}{l}192(64) \\
58(19.3)\end{array}$ \\
\hline $\begin{array}{l}\text { Best way of prevention } \\
\text { Netted windows } \\
\text { Treated nets. } \\
\text { Pyrethrum sprays } \\
\text { Chemoprophylaxis } \\
\text { Others }\end{array}$ & $\begin{array}{l}17(11.5) \\
38(25.8) \\
27(18.3) \\
21(14.3) \\
44(29.3)\end{array}$ & $\begin{array}{l}21(15.5) \\
49(36.2) \\
25(18.5) \\
30(22.2) \\
10(7.4)\end{array}$ & $\begin{array}{l}38(13.4) \\
87(30.8) \\
52(18.4) \\
51(18) \\
54(19.1)\end{array}$ & $\begin{array}{l}12(8.28) \\
68(46.9) \\
26(17.9) \\
05(3.45) \\
34(23.4)\end{array}$ & $\begin{array}{l}10(10.3) \\
35(36) \\
20(20.6) \\
12(12.4) \\
20(20.6)\end{array}$ & $\begin{array}{l}22(11.4) \\
103(53.6) \\
46(23.9) \\
17(8.85) \\
54(28.1)\end{array}$ \\
\hline $\begin{array}{l}\text { Can malaria be treated? } \\
\text { Yes } \\
\text { No }\end{array}$ & $\begin{array}{l}146(97.3) \\
04(2.67)\end{array}$ & $\begin{array}{l}142(94.6) \\
08(5.3)\end{array}$ & $\begin{array}{l}288(96) \\
12(4)\end{array}$ & $\begin{array}{l}150(0) \\
0(0)\end{array}$ & $\begin{array}{l}133(88.6) \\
17(11.3)\end{array}$ & $\begin{array}{l}283(94.3) \\
17(56.7)\end{array}$ \\
\hline $\begin{array}{l}\text { Best way to treat malaria } \\
\text { Self medication } \\
\text { Hospital/clinic } \\
\text { Local herbs } \\
\text { Chemist/pharmacy } \\
\text { Prayers } \\
\text { Others }\end{array}$ & $\begin{array}{l}96(65.7) \\
03(2.1) \\
21(14.3) \\
06(4.1) \\
0(0) \\
24(16.4)\end{array}$ & $\begin{array}{l}14(9.86) \\
108(76) \\
04(2.82) \\
0(0) \\
0(0) \\
0(0)\end{array}$ & $\begin{array}{l}110(38.1) \\
111(38.5) \\
25(8.68) \\
06(2.08) \\
0(0) \\
24(8.3)\end{array}$ & $\begin{array}{l}105(70) \\
23(15) \\
16(10.6) \\
06(40) \\
0(0) \\
0(0)\end{array}$ & $\begin{array}{l}20(15) \\
64(48.1) \\
04(3.0) \\
0(0) \\
8(6.0) \\
0(0)\end{array}$ & $\begin{array}{l}125(44.1) \\
87(30.7) \\
20(7.0) \\
06(2.12) \\
8(2.82) \\
48(16.9)\end{array}$ \\
\hline
\end{tabular}

Table 4: Socio-economic Effects of Malaria among the Respondents

\begin{tabular}{|c|c|c|c|c|c|c|}
\hline & \multicolumn{3}{|c|}{ LASU No (\%) } & \multicolumn{3}{|c|}{ AOCOED No (\%) } \\
\hline & Male & Female & Total & Male & Female & Total \\
\hline \multicolumn{7}{|l|}{$\begin{array}{l}\text { Class } \\
\text { absenteeism }\end{array}$} \\
\hline Yes & $86(57.3)$ & $78(52)$ & $164(54.6)$ & $140(93.3)$ & $74(49.3)$ & $214(71.3)$ \\
\hline No & $64(42.6)$ & $72(48)$ & $136(45.6)$ & $10(6.67)$ & $76(50.7)$ & $86(28.6)$ \\
\hline \multicolumn{7}{|l|}{$\begin{array}{l}\text { Amount spent } \\
\text { on drugs }\end{array}$} \\
\hline N100-500 & $64(42.7)$ & $70(46.6)$ & $134(44.6)$ & $57(38)$ & $76(50.6)$ & $133(44.3)$ \\
\hline N600- 1000 & $54(36)$ & $46(30.7)$ & $100(33.3)$ & $63(42)$ & $32(21.3)$ & $95(31.6)$ \\
\hline Above N1000 & $32(21.3)$ & $34(22.7)$ & $66(22)$ & $30(20)$ & $42(28)$ & $72(24)$ \\
\hline \multicolumn{7}{|l|}{$\begin{array}{l}\text { Father's } \\
\text { Occupation }\end{array}$} \\
\hline Trader & $30(20)$ & $16(10.7)$ & $46(14.7)$ & $59(39.3)$ & $24(16)$ & $83(27.6)$ \\
\hline Medical & $07(4.7)$ & $13(8.7)$ & $20(6.67)$ & $06(4)$ & $11(7.3)$ & $17(5.7)$ \\
\hline Lawyer & $07(4.7)$ & $0(0)$ & $07(2.3)$ & $02(1.33)$ & $0(0)$ & $02(0.67)$ \\
\hline Banker & $08(5.3)$ & $0(0)$ & $08(2.67)$ & $14(9.33)$ & $0(0)$ & $149(4.67)$ \\
\hline Public officer & $53(35.3)$ & $83(55.3)$ & $136(45.3)$ & $40(26.7)$ & $83(55.3)$ & $123(41)$ \\
\hline Farmer & $07(4.7)$ & $0(0)$ & $07(2.3)$ & $06(4)$ & $05(3.33)$ & $11(3.67)$ \\
\hline Unemployed & $28(18.6)$ & $26(17.3)$ & $54(18)$ & $13(15)$ & $0(0)$ & $13(4.3)$ \\
\hline Others & $10(6.67)$ & $12(8)$ & $22(7.3)$ & $10(6.67)$ & $27(18)$ & $37(12.3)$ \\
\hline \multicolumn{7}{|l|}{$\begin{array}{l}\text { Mother's } \\
\text { Occupation }\end{array}$} \\
\hline Trader & $83(55.3)$ & $68(45.3)$ & $151(50.3)$ & $110(73)$ & $60(40)$ & $170(56.6)$ \\
\hline Medical & $05(3.33)$ & $18(12)$ & $23(7.6)$ & $03(2)$ & $17(11.3)$ & $20(6.66)$ \\
\hline Lawyer & $03(2)$ & $0(0)$ & $03(1)$ & $18(12)$ & $0(0)$ & $0(0)$ \\
\hline Banker & $04(2.67)$ & $0(0)$ & $04(1.33)$ & $04(2.7)$ & $0(0)$ & $0(0)$ \\
\hline Farmer & $0(0)$ & $0(0)$ & $0(0)$ & $06(4)$ & $0(0)$ & $06(2)$ \\
\hline Public officer & $14(9.33)$ & $63(42)$ & $77(25.6)$ & $09(6)$ & $65(43.3)$ & $74(24.6)$ \\
\hline $\begin{array}{l}\text { Housewife } \\
\text { Others }\end{array}$ & $41(27.3)$ & $1(0.66)$ & $42(14)$ & $0(0)$ & $8(5.3)$ & $08(2.67)$ \\
\hline
\end{tabular}




\section{DISCUSSION}

Adequate knowledge was expected among students about malaria. In this study, it appears that LASU students had a better knowledge of the cause, prevention and treatment of malaria than AOCOED students. Okwa and Ibidapo (2010), reported in a preliminary study, on malaria situation in LASU. Surprisingly, only $58.3 \%$ of the students investigated knew the cause of malaria. Conversely, the knowledge and perception of the cause of malaria was higher in this present study. No significant difference occurred between the two schools and between male and female respondents. This is similar to the results of a study carried out by Babalola and Lamikanran (2007) in which no significant difference existed between male and female.

Self medication has long been common among students (Anumudu et al., 2006). Okwa and Ibidapo (2010) also reported that students believed in the use of self medication and prayers. They observed that students had the habit of tolerating malaria symptoms and embarking on self medication, until they become critically sick. This was also the observation made in this study and in AOCOED where this study was been carried out for the first time. Recommendation of drug education intervention is necessary to curb the menace of self medication among students.

In an earlier study, Okwa and Ibidapo (2010) observed that majority of infected students who paricipated were aged between 22-23years and more females were infected. In this present study, majority of the infected students were in their second year (42.2\%) with females (44.8\%) having a higher prevalence, except that male respondents had history of more malaria cases than females in this study. Okwa and Ibidapo (2010) also observed that headache was the most common symptoms recognized by students, whenever they had malaria. But in this study, headache was the third symptom mentioned to fever and weakness.

Malaria undermines effectiveness of investment in education by reducing learning capacity (Worrall et al., 2003). A single bout of malaria costs an equivalent of more than 10 working days in Africa (Breman, 2001). In 1995, an estimate of the total cost of malaria was more than $\$ 18000$ million. Malaria causes a loss of 12 billion dollars per year in loss Gross Domestic Product (GDP) and only a fraction of this amount could help control it (WHO,
1999). In this study, malaria has effect on class absenteeism and long term effects on academic performance. Brabin and Brabin (2005) stated that behavioural change including appropriate health seeking practices is essential for disease reduction and failure to prioritise adolescent and young adults' health may seriously limit the success of disease programs. Educational institutions should enlighten their students on health issue, avoiding mosquito bites, prompt and early reporting of malaria symptoms and proper use of malaria drugs. Students need to be reminded to clear bushes and stagnant pools around their hostels. In conclusion, this study has emphasised that malaria constitute a threat to the health and academic status of students. The study also identifies that poor knowledge and perception of malaria may lead to less concern about its prevention among this population. The socioeconomic effect can be incorporated in health education strategies to increase compliance with preventive methods such as the use of integrated bed nets. The study maintains that the battle against malaria is a big challenge to public health today.

\section{ACKNOWLEDGEMENTS}

We wish to thank the LASU and AOCOED students that participated by filling the questionnaires. We are also grateful to the university authority for permission to conduct the research.

\section{REFERENCES}

Anumudu CI, Adepoju A, Adediran M, Adeoye 0, Kassim A, Oyewole I and Nwuba RI( 2006). Malaria Prevalence and Treatment Seeking Behavior of Young Nigerian Adults. Ann Afr Med. 5(2) 82-88

Babalola 00 and Lamikanran A (2007). The Response of Students to Malaria and Therapy in a University in South-western Nigeria. Res Soc Admin Pharm. 3(3) 351-362

Brabin L and Brabin BJ (2005). HIV, Malaria and Beyond: Reducing the Disease Burden of Adolescents. Malaria J. 4:2-18

Breman, JG (2001). The Ears of the Hippopotamus Manifestations, Determinants and Estimates of the Malaria Burden. Am J Trop Med Hyg. 64: 1-11

Elzubier AG, Ansari EHH and Nour El MH (1997). Knowledge and Misconceptions of Malaria among Secondary School Students in Kassala, Eastern Sudan. J Roy Soc Prom Hlth. 117(6): 381-385 
Fawole OI and Onadeko MO (2001). Knowledge and Home Management of Malaria Fever by Mothers and Care Givers of Fewer than Five Children. West Afr J Med. 20:152-157

Fernando SD, Guyawardena DM, Bandara D, DeSilva $\mathrm{R}$, Carter KN, Mendis KN and Wickermasinghe AR (2003). The Impact of Malaria Attacks on the School Performances of Children. Am J Trop Med Hyg. 69(6):582-588

Lalloo DG (2004). Malaria in Adolescence. Issues in Adolescents and Development. Department of Child and Adolescent Health and Development. WHO Geneva. Pp: 20

Lalloo DG, Oluloya P and Olliaro P (2006). Malaria in Adolescents. Burden of Disease, Consequences and Opportunities for Intervention. Lancet Infect Dis. 6 (12): 780-793

Leighton C and Foster R (1993). Economic Impact of Malaria in Kenya and Nigeria. Applied Research Paper No. 6. Abt Associates Inc. In Collaboration with Vector Biology Control Project, Medical Services Corporation International. Pp:222

Matta S, Khokhar A and Sachdev TR (2004). Assessment of Knowledge about Malaria among Patients Reported with Fever: A Hospital-based Study. J Vect Borne Dis. 41:27-31

Morenikeji OA (2009). Perception and Management of Malaria in Secondary Schools in a Nigerian City. Pak J Med Sci. 25(3):508-511

Muala AS and Chimalizeni Y (2004). Knowledge, Attitudes and Practices towards Malaria among Primary School Pupils in Ndirande, Malawi. Trop Doc. 34(2) 90-93

Najera JA and Hempel J (2006). The Burden of Malaria. CTD/Mal/ 96.10.Pp: 35

Ndawala J, Kalanda G and Mahy M (2000). Malawi MDHS. Data Analysis: Malawi National Statics Office. 222:http://www.nso.malawi/net
Nelson GS (1978).Comments and Discussions I. on Medical Aspects "In the Relevance of Parasitology to Human Welfare Today (Eds. Taylor AER and Miller R. Ibadan University Press. Pp: 15-23

Okwa 00, Akinmolayan IF, Carter V and Hurd H (2009). Transmission Dynamics of Malaria in Nigeria. Ann Afr Med. 8 (1):1-9

Okwa 00 and Ibidapo CA (2010). Malaria Situation, Perception of Cause and Treatment in a Nigerian University. J Med Med Sci. 1(6) 213-222

Onwujekwe O, Chima R and Okonkwo P (2000). Economic Burden of Malaria illness on Households versus that of all other illness Episodes: A Study in Five Malaria Holo-endemic Nigerian Communities. Health Policy. 54:143-159

Peetermanns WE and Wijingaerden EV (2001). Implementation of Pre-travel Advice. Good for Malaria; Bad for Diarrheoa. Acta Clin Belg. 56(5):284-288

Sachs J and Malaney P (2002). The Economic and Social Burden of Malaria. Nature. 415:680- 685

Salako LA (2001). Treatment of Childhood Fevers and Other illnesses in Three Rural Nigerian Communities. J Trop Pediatr. 47:230-238

Ukoli FMA (1992). The Prevention and Control of Parasitic Disease in Tropical Africa: The Main Issues. University Press PLC, Ibadan. Pp: 199

Worrall E, Basu S and Hanson K (2003). The Relationship between Socio-economic Status and Malaria: A Review of the Literature for Ensuring Malaria Control Interventions to reach the Poor.September $5^{\text {th }}-6^{\text {th }}, 2003$. London School of Hygiene and Tropical Medicine.

World Health Organization (WHO) (1999). Fact sheet No. 94: Malaria 